\title{
A infância sem segredos: a noticiabilidade jornalística do crime de exploração sexual de crianças e adolescentes*
}

Maria Amélia Tostes Filgueiras Campos ${ }^{1}$

Carmen Dulce Diniz Vieira ${ }^{2}$ Joaquim Antônio César Mota ${ }^{3}$

CAMPOS, M.A.T.F.; VIEIRA, C.D.D.; MOTA, J.A.C. Childhood without secrets: the journalistic newsworthiness of the crime of sexual exploitation of children and adolescents. Interface - Comunic., Saude, Educ., v.13, n.30, p.17-29, jul./set. 2009.

By selecting the ordinary events that society needs to know about and the ones that it can ignore, and through coding these events in news format, journalism makes a type of experience of the surrounding world available to the public. Increasingly, communication tools are the means with which civilized man experiences events. Knowledge of the nature of this experience is one way in which society can relate to its own functioning and condition. In this study, we examined 15 reports published in the "Estado de Minas" newspaper in 2004, focusing on a special report on "Stolen Childhood". Through a strategy of esthetic deconstruction and studying the news narrative relating to stolen childhood, along with content analysis on the material, it became evident that the news value of the transgression was what determined the journalistic newsworthiness of the sexual crimes committed against children and adolescents.

Keywords: Sexual violence. Child sexual maltreatment. Communication media. Child. Adolescent.
Ao selecionar os acontecimentos ordinários que a sociedade deve conhecer e os que ela deve ignorar, e ao codificar esses acontecimentos sob a forma de notícia, o jornalismo disponibiliza para a coletividade um tipo de experiência com o mundo que a cerca. Cada vez mais, os dispositivos comunicativos são os meios de experiência do homem civilizado. Conhecer a natureza dessa experiência é uma forma de a sociedade se apropriar do seu próprio funcionamento e de sua própria condição. Esta pesquisa trabalha com 15 reportagens publicadas pelo Jornal Estado de Minas, em 2004, especialmente com a grande reportagem Infância Roubada. Por meio da estratégia de desconstrução estética e da narrativa noticiosa de Infância Roubada, bem como da análise de conteúdo do material, fica evidenciado que o valornotícia da transgressão é o que justifica a noticiabilidade jornalística dos crimes sexuais cometidos contra crianças e adolescentes.

Palavras-chave: Violência sexual. Maus-tratos sexuais infantis. Meios de comunicação. Criança. Adolescente.

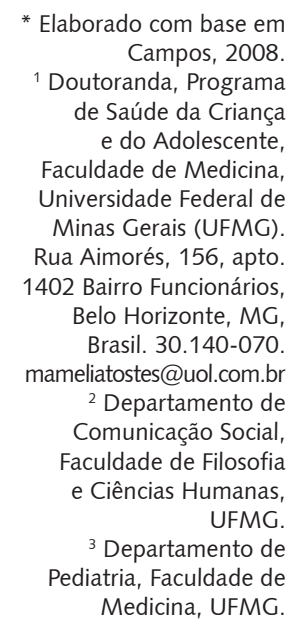




\section{Sobre os campos da saúde e da comunicação}

Saúde e Comunicação são dois campos sociais que muito têm em comum, mas nem sempre reconhecem essa afinidade e essa necessidade de se entrelaçarem para poderem, cada qual, desempenhar melhor seu papel em sociedade. O campo da saúde, se quiser dialogar com a sociedade e ser eficiente sob o ponto de vista social, necessita que seus princípios, estratégias, regras e conceitos sejam entendidos pela coletividade. A instância capacitada e autorizada socialmente a promover esse entendimento é, fundamentalmente, a da comunicação social. Esta, por sua vez, só existe para, pelo e por causa do público. A saúde é gênero de primeira necessidade para a sociedade e, portanto, é essencial às finalidades comunicativas, cujos dispositivos necessitam de ter sempre um canal aberto com o campo da saúde.

O campo da comunicação se notabiliza por ser um campo especialista e credenciado socialmente a traduzir significados e sentidos de outros campos, como os da saúde, da política, da educação. Isso porque o campo comunicativo só existe se relacionado a outros campos. A comunicação é um dispositivo que funciona nas relações sociais, promovendo interações, essa é a sua natureza.

Não bastasse isso, o campo comunicacional e o sistema público nacional de saúde possuem afinidades fundamentais em seus princípios de universalidade, equidade, integralidade, descentralização, hierarquização e participação, como enfatizam Araújo e Cardoso (2007), uma vez que esses dois campos perseguem os mesmos ideais como democracia e bem-estar público. À comunicação interessa que todos tenham direito à informação; na saúde, a luta é pela universalização do atendimento; para a comunicação e para a saúde, é fundamental fazer circular os dispositivos de produção informativa e de saúde, hierarquizando e descentralizando essa produção; bem como promover a participação e a articulação com outros saberes.

A aproximação entre comunicação e saúde não só é legítima como necessária para o desenvolvimento e o aprimoramento dos dois campos, pois a ambos cabe defender e lutar pelos mesmos interesses. Comunicação e saúde se entendem em seus fundamentos, necessitando, portanto, "de novos aportes, outros atores, outras perspectivas [...] de mais reconhecimento, pois sem essa dimensão simbólica, tudo o mais se fragiliza" (Araújo, Cardoso, 2007, p. 130).

Aproximar esses dois campos de saberes, em uma pesquisa acadêmica, foi, portanto, desde o início, uma ideia animadora e, nesse sentido, a decisão de seguir o viés da noticiabilidade no jornalismo pareceu oportuna, uma vez que a noticiabilidade - estudada especialmente pela corrente teórica do newsmaking, mas abordada por todas as teorias do processo comunicativo de massa - é um dos eixos de estudo do jornalismo que melhor esclarece o processo noticioso e que mais variáveis angaria ao longo do percurso trilhado pela notícia. Demonstrar os processos internos de produção da notícia a partir de um tema atual e de interesse para a saúde, como a exploração sexual da criança e do adolescente, foi um desafio e uma maneira de estabelecer um diálogo profícuo e promissor entre os dois campos.

A análise da noticiabilidade acaba por desembocar na relação cotidiana e sintonizada que existe entre a sociedade e os dispositivos comunicativos. Ao nos debruçarmos sobre o modo como o jornalismo seleciona os acontecimentos e os transforma em notícias, estamos, no final das contas, nos intrometendo na conversa ininterrupta que os veículos de comunicação estabelecem com a sociedade. No caso deste trabalho, o tema da conversa é a exploração sexual infanto-juvenil. Aqui, o que se objetiva é ampliar essa conversa para o campo da saúde, a fim de que os seus especialistas possam se familiarizar com alguns dos conceitos e dos valores comunicativos.

O terreno da noticiabilidade, no jornalismo, é vasto. Ele começa na seleção do acontecimento arregimentando inúmeras variáveis objetivas e subjetivas -, passa pela confecção propriamente dita da notícia e pela sua divulgação para o público, envolvendo até o seu consumo pela sociedade e as possíveis consequências advindas por esse consumo, ou seja, a sua repercussão social. Definiu-se que essa pesquisa se ateria às análises da noticiabilidade jornalística pertinentes ao processo seletivo e produtivo da notícia.

Por produção noticiosa está-se referindo aqui à rotina cotidiana que a notícia percorre a partir do momento em que ela é selecionada: a definição de pauta, o período de apuração, o momento da redação, o trabalho de edição e a atividade de diagramação (disposição visual) na página do jornal, 
aprontando o jornal para a impressão e o consumo.

Compreendendo que os critérios utilizados pelo jornalismo para informar a sociedade são expedientes que acompanham todo o percurso noticioso e se modificam ao longo das fases pelas quais passa a notícia, há que se ressaltar, entretanto, que as investigações sobre o assunto são um esforço sempre débil e sem garantias. Isso porque os agentes de noticiabilidade que interferem nos momentos de seleção, de produção e de consumo da notícia não são apenas objetivos, mas também subjetivos. E mais: o encadeamento noticioso, embora possua, sim, linearidade produtiva, não acontece, na prática, linearmente, ou seja, cada fase da notícia é perpassada e influenciada sempre por todas as suas outras fases, fazendo da produção noticiosa um processo global e não fragmentado em sua execução.

\section{As estratégias de análise do objeto de estudo}

Para cumprir com as finalidades da pesquisa, foram selecionadas as 15 principais reportagens publicadas, ao longo do ano de 2004, pelo Jornal Estado de Minas (JEM) - sediado em Belo Horizonte, e com o maior índice de circulação em Minas Gerais -, que tratavam do tema da exploração sexual de crianças e adolescentes. Esse recorte noticioso resultou da utilização do banco de dados da Organização Não-Governamental Oficina de Imagens, braço mineiro da Rede ANDI Brasil (Agência de Notícias dos Direitos da Infância) e localizada na capital mineira, que, diariamente, varre eletronicamente os principais jornais impressos do Estado ${ }^{4}$, selecionando todas as inserções noticiosas sobre crianças e adolescentes.

O material de pesquisa foi investigado sob os parâmetros gráficos e de edição próprios do jornalismo, levando em consideração o grau de evidência da noticiabilidade para o leitor. Foi conceituada como "A noticiabilidade ao alcance do olhar". Para essa análise, lançou-se mão de duas categorias: a categoria visual - que corresponde ao que, no jornalismo, se denomina de diagramação - e a categoria editorial. A categoria visual foi denominada de "Aspectos da diagramação" e a categoria editorial, de "Aspectos da edição". A primeira categoria compreendeu sete subcategorias: espaço ocupado na página; fotografia; cor; destaque; box; capa do Caderno Gerais e localização espacial das matérias que ocuparam menos de uma página inteira. A segunda categoria se subdividiu em quatro outras subcategorias: assinatura de matéria; versal; fontes e menções aos Estatuto da Criança e do Adolescente.

A idéia norteadora dessa análise é a de que a matéria jornalística organizada e estampada na página do jornal, para ser consumida pelo público, possui códigos específicos do jornalismo que podem ser decodificados com razoável facilidade por um leitor que está acostumado a ler jornais diariamente e, portanto, familiarizado com a estética da notícia. É uma noticiabilidade que o leitor reconhece tão logo ele abre o jornal. Afinal, o que motivou esse trabalho, antes de mais nada, foi a intenção de fazer de todo cidadão um bom decodificador de informações jornalísticas. A página de jornal é o lugar mais simples e evidente da noticiabilidade. Era fundamental levar a estética das notícias para a análise da noticiabilidade jornalística.

Pode-se dizer também que essa é a face mais visível e menos controversa da noticiabilidade. O modo como a notícia se apresenta para o público diz muito sobre os seus valores-notícia e seus critérios de noticiabilidade. A análise do conjunto das 15 reportagens sob o referencial estético da notícia foi uma oportunidade de desvendar alguns dos fundamentos que o jornalismo utiliza para fazer da notícia um produto específico e único. 
Já as investigações sobre os critérios de noticiabilidade e os valores-notícias utilizados pelo jornalismo na seleção e na produção textual das notícias sobre o crime de exploração sexual infanto-juvenil tomaram por base não mais a totalidade das matérias selecionadas, mas apenas uma reportagem, eleita como a reportagem que culminou o processo noticioso sobre o tema de estudo na imprensa mineira, no ano de 2004: Infância Roubada. ${ }^{5}$

Entendida como acontecimento capaz de propiciar conhecimento e experiência ao leitor, a grande reportagem Infância Roubada foi analisada com a finalidade de demonstrar por que o jornalismo elege o crime de exploração sexual de crianças e adolescentes como acontecimento noticiável, e como ele produz e exibe esse tipo de matéria para o público. Na medida em que a notícia é resultado de um processo objetivo, mas também subjetivo, a pesquisa se ocupou ainda da análise dos questionários respondidos pela equipe de sete jornalistas responsável pela produção de Infância Roubada. Todos os entrevistados assinaram o Termo de Consentimento Livre e Esclarecido submetido e aprovado pelo Comitê de Ética.

As reportagens selecionadas para a pesquisa abordam um assunto que confronta a sociedade consigo mesma; trazem à luz o que, em princípio, não deveria ser mostrado, revelam um mundo que seria preferível que não saísse da escuridão. A exploração sexual de crianças e adolescentes é um problema social que evidencia uma inadequação do funcionamento social.

Minas Gerais é o Estado com maior número de "pontos" de exploração sexual de crianças e adolescentes do país. Em 2004, a Polícia Rodoviária Federal apresentava um levantamento inédito, no qual relatava que o Estado detinha $74(13,3 \%)$ de um total de 553 "pontos" existentes ao longo de sessenta mil quilômetros de estradas federais (Odilla et al., 2004). No mês de maio de 2007, novo relatório da PRF e da Organização Internacional do Trabalho (OIT) atualizava esses números. Minas Gerais continuava a deter o maior mercado de sexo infanto-juvenil do país, agora com nada menos do que 290 pontos de um total de 1.819 pontos instalados na malha rodoviária federal.

Em troca de suco, coxinha, pastel, um saco de bolacha, um prato de comida ou cobrando preços que variam entre $R \$ 0,50$ a $R \$ 10,00$, crianças de dez anos de idade vendem seu corpo a clientes - caminhoneiros, em sua maioria - que, mesmo casados e pais de filhos, não sentem o menor constrangimento pelo que fazem. Ao contrário, vangloriam-se por encontrarem crianças que cobram tão pouco por um programa em sua companhia. Sob o seu ponto de vista, este é um sinal de que eles "valem a pena" e, portanto, não representam nenhum sacrifício para as meninas. Depoimentos nesse sentido foram registrados, em 2004, pela cobertura jornalística do Jornal Estado de Minas investigada pela pesquisa (Odilla et al., 2004).

O que todos nós gostaríamos é de que não houvesse crimes desse tipo em nossa sociedade. E a tendência da coletividade é afastar de si qualquer ameaça a sua condição de harmonia e bem-estar. Por que será que reportagens dessa natureza são produzidas pela imprensa? Por que o jornalismo ousa revelar o que a sociedade prefere esconder e, assim mesmo, a imprensa se sustenta como uma instância social autorizada, respeitada e com credibilidade perante a coletividade?

\section{Noticiabilidade: do que se trata}

No transcorrer de um dia, muita coisa acontece no mundo inteiro, no nosso país, na nossa região, na nossa cidade, na nossa rua, na nossa comunidade,

\footnotetext{
${ }^{5}$ Reportagem publicada pelo Caderno Gerais do JEM, em 02 de maio de 2004 (Odilla et al., 2004).
} 
e apenas alguns desses acontecimentos chegam até o nosso conhecimento. Isso quer dizer que existe uma instância de comunicação social - a imprensa - que seleciona o que deve ser informado à sociedade.

Se há uma seleção anterior àquela operacionalizada por nós que é feita, cotidianamente, pelos dispositivos comunicativos, e se essa seleção define o que a coletividade deve saber e o que ela deve ignorar, estabelecendo, em última análise, a que tipo de experiência a sociedade vai poder ter acesso ou não, então é muito importante que conheçamos o modo como a mídia e, especialmente, a imprensa, efetua essa escolha e produz as informações.

A noticiabilidade se constitui da propriedade-habilidade-capacidade que o jornalismo detém de transformar algumas ocorrências em notícias com base em requisitos específicos exigidos dos acontecimentos ordinários. A noticiabilidade é então a condição de notícia de um evento sob a ótica do jornalismo.

Na noticiabilidade, interferem variados fatores relacionados à produção noticiosa, que vão desde a qualidade do acontecimento (seus valores-notícia), passando pela percepção individual e de classe do jornalista, bem como pelo conjunto de características do veículo informativo ao qual pertence o profissional, até as condições técnicas de apuração e de confecção da notícia, nas redações. Um processo extremamente complexo e situado em um horizonte histórico, político, econômico e social.

A noticiabilidade corresponde então

ao conjunto de critérios, operações e instrumentos com os quais os aparatos de informações enfrentam a tarefa de escolher cotidianamente, de um número imprevisível e indefinido de acontecimentos, uma quantidade finita e tendencialmente estável de notícias. (Wolf, 2005, p.195-6)

Os critérios utilizados pelo jornalismo para conferir noticiabilidade a determinados acontecimentos são denominados de critérios de noticiabilidade. Esses critérios atravessam todo o processo de produção da notícia - da seleção ao consumo - e são mais ou menos prevalentes de acordo com a fase por que passa a notícia no seu encadeamento produtivo. Selecionar o fato como noticiável requer determinados critérios. Apurar e produzir a notícia envolve critérios específicos. Tornar pública a informação jornalística já arregimenta outros critérios.

A importância e o interesse gerados por um acontecimento são, de acordo com Wolf (2005), os critérios substantivos da notícia, isto é, os critérios que mais proximidade estabelecem com os atributos próprios dos acontecimentos. Que atributos seriam esses? São os valores portados pelos acontecimentos, os quais Ihe possibilitam condições de serem noticiados: os valores-notícia. Trata-se da bagagem própria que cada evento porta consigo e que, sob a égide dos critérios substantivos do jornalismo, classifica ou desclassifica o acontecimento como noticiável.

Os valores-notícia são "um componente da noticiabilidade". Tais valores, embora apareçam listados, destacados e individualizados, "operam na prática de modo complementar" e funcionam "em maços" (Wolf, 2005, p.202). Além do mais, são valores que permeiam todo o processo de produção informativa e se ajustam completamente à rotina do trabalho jornalístico de forma a facilitála ao invés de complicá-la.

Os valores-notícia, ainda que apresentem "uma forte homogeneidade" dentro do campo jornalístico, possuem, de acordo com Wolf, uma "natureza dinâmica". Isso quer dizer que os valoresnotícia são reajustados e redefinidos em função das necessidades sociais e da capacidade de os aparatos informativos responderem a elas (Wolf, 2005).

Há que se ponderar que quanto maior a quantidade de valores-notícia de um acontecimento referendados pelos critérios substantivos, maior a sua autonomia em relação aos demais critérios de noticiabilidade, pois a importância social de que ele se reveste o torna menos vulnerável às avaliações e pontos de vistas dos profissionais da mídia, bem como às condições de natureza operacional impostas pelos veículos de informação para a sua transformação em notícia. Certamente que o caráter substantivo de um fato está sempre relacionado a um determinado horizonte social.

De acordo com Traquina (2005), os valores-notícia adotados pelos critérios substantivos são: a 
morte; a notoriedade (o nome e a posição da pessoa em sociedade são importantes como fatores de noticiabilidade); a proximidade (tanto geográfica quanto cultural); a relevância (qual o impacto que o acontecimento tem sobre a vida das pessoas); a novidade; o tempo (enquanto atualidade, enquanto demarcação de uma data significativa e enquanto duração/persistência do acontecimento); a notabilidade (capacidade de o acontecimento ser visível ou tangível às pessoas, podendo ser registrada na quantidade de pessoas envolvidas no fato; na inversão, ou melhor, no modo de contrariar o normal; no insólito ou na capacidade de surpreender as pessoas; nas falhas e nos acidentes; no excesso ou na escassez); o inesperado; o conflito ou a controvérsia; a infração (violação ou transgressão das regras); e o escândalo (Traquina, 2005).

Diante dos valores-notícia reconhecidos pelo jornalismo, os critérios substantivos são os mais consensuais de um acontecimento, uma vez que eles já estão respaldados pelo senso comum de uma determinada sociedade e elegem fatos que normalmente não necessitam que a imprensa os selecione; eles se impõem por si mesmos à cobertura informativa dos veículos midiáticos, e qualquer negligência da mídia, nesses casos, pode custar a sua credibilidade junto ao público.

Ao comportarem valores em si mesmos que são respaldados e endossados, consensualmente, pela sociedade, os critérios substantivos são também os mais duradouros de um acontecimento porque, se eles carregam consigo o senso comum de uma sociedade, eles não mudam da noite para o dia e nem mudam homogeneamente. Essa durabilidade dos critérios substantivos é o que garante um elevado grau de conservadorismo dos valores-notícia através dos tempos. Assim, os acontecimentos ricos em valores-notícia reconhecidos pelos critérios substantivos atravessam os anos sendo, em maior ou menor grau, noticiados pela imprensa.

Os valores-notícia dos acontecimentos contemplados pelos critérios substantivos do jornalismo são os responsáveis, em grande medida, pela sua noticiabilidade, e esses valores são mais endossados pela imprensa na sua interação com a sociedade do que propriamente criados por ela.

O que a imprensa faz com muita habilidade é superestimar ou subestimar, valorizar ou desvalorizar o caráter substantivo de um fato de acordo com: seu formato midiático (se é jornal, rádio, tv etc.), seu público, os veículos que lhe fazem concorrência, a sua estrutura física e sua capacidade de cobertura e, mesmo, sua linha editorial e ideológica. Pode-se afirmar que a noticiabilidade de um evento se apóia, por um lado, nas expectativas sociais a ele relacionadas e, por outro, nas especificidades da produção informativa.

\section{Notícia: um produto socialmente consensual e consonante}

As notícias são moldadas dentro de uma relação consensual estabelecida com a sociedade, ou seja, os jornalistas ou os media não são especialistas em criar notícias, eles normalmente as produzem a partir da relação por eles mantida com o consenso social.

Hall (1993) explica a natureza consensual de uma sociedade como uma espécie de "assunção de fundo" ou de "quadros de referência de fundo", a partir dos quais se torna possível obter o que ele denomina de "mapa cultural" dessa sociedade, isto é, seu "mapa de significados" (p.226). O "mapa de significados" de uma sociedade é, para esse autor, a sua base referencial de valores e de comportamentos: como essa sociedade se constrói como tal; como ela se pensa; seus parâmetros de normalidade e, consequentemente, de anormalidade; enfim, o que essa sociedade é, e como ela funciona.

Funcionando como decodificadores sociais dos fatos fora do comum, invulgares, imprevisíveis, conflituosos e problemáticos, os media absorvem e constroem, ao mesmo tempo, o consenso social. A sociedade necessita entender o seu entorno, cada vez mais segmentado, especializado e complexificado. Esse entendimento é que lhe garante uma condição, pelo menos imaginária, de harmonia e homogeneidade.

Não haveria sociedade se as discrepâncias sobressaíssem mais do que as semelhanças. É, portanto, fundamental ao funcionamento social essa idéia de que existe um consenso, isto é, um entendimento 
geral e amplo sobre o mundo que nos cerca, partilhado por todos os membros de uma sociedade e capaz de promover uma sensação de que tudo está sob controle.

Essa familiaridade e essa proximidade proporcionadas pelo jornalismo à sociedade, sobre os acontecimentos ordinários, é obtida pela condição de consonância estabelecida entre o fato novo e os fatos antigos. Traquina (2005) analisa a consonância como uma estratégia de construção da notícia destinada a inserir o acontecimento em uma narrativa já estabelecida. Com isso, ele quer dizer que a consonância aproveita o conhecimento que o público possui sobre o assunto e, consequentemente, o interesse já despertado em sociedade, para tratar do tema com base em uma ótica inovadora. A consonância no jornalismo ocorre então quando "o 'novo' acontecimento é inserido numa 'velha' estória" (Traquina, 2005).

\section{A noticiabilidade do crime}

Na medida em que a sociedade requisita, por uma questão mesma de sobrevivência, entender a si própria e manter o seu funcionamento sob controle, afastando tudo o que possa ameaçar a sua noção de corpo homogêneo e consistente, o crime surge como um desvio social a ser combatido e repelido.

A lei incorpora a vontade de uma sociedade e lhe fornece "a definição básica de quais são as ações que são aceitáveis ou não" (Hall, 1993, p.237); estabelece as fronteiras entre a normalidade e a anormalidade, entre o comum e o incomum, entre a ordinariedade e a extraordinariedade dos acontecimentos sociais.

Partindo da noção de que a notícia se instala justamente naquilo que rompe com a normalidade das coisas, "o crime é, quase por definição, 'notícia'" (Hall, 1993, p.237). O crime, ao ser noticiado, evoca as ameaças que a sociedade tanto teme e, ao mesmo tempo, "reafirma a moralidade consensual da sociedade" (p.237).

A violência não é uma prerrogativa de qualquer um, mas apenas do Estado, que a ela recorre sempre que o indivíduo, a propriedade e o próprio Estado sofram quaisquer abalos, lembra Hall (1993). Sob esse ponto de vista, esse autor considera impossível que a violência não seja, portanto, um tema social extremamente valorizado pelos media. Os que se queixam de que as notícias contêm demasiada violência "não compreendem o que são as notícias" (Hall, 1993, p.239).

Os relatos noticiosos sobre crimes se relacionam também com o gosto do público pelo que é negativo. Traquina (2005) informa que, no ano de 1600, quando as "folhas volantes" - forma prémoderna do jornal - predominavam na Europa e até na América Central, os assuntos noticiáveis eram os assassinatos, os quais representavam 1/3 das notícias. Segundo ele, havia um fascínio, na época, pelos homicídios e pelos enforcamentos. O insólito - àquela altura representado pelos milagres, o aparecimento de monstros, as práticas feiticeiras e as guerras - e as celebridades dominavam o restante do espaço noticioso das "folhas volantes" (Traquina, 2005).

Em 1965, um estudo da dupla Johan Galtung e Marie Holmbose Ruge (apud Traquina, 2005) destacou a negatividade dos acontecimentos como um dos principais fundamentos das notícias. De acordo com o autor, esses estudiosos explicam a preferência da imprensa por acontecimentos negativos pelo que eles portam de inesperado, de imprevisível e de raro e pelo que esses acontecimentos possuem de consensual e inequívoco em sociedade. Em outras palavras, a negatividade concilia mais a sociedade do que a positividade. Há uma melhor possibilidade de a sociedade acordar entre si sobre o que é ruim, triste, indesejável, impraticável, imoral e revoltante para os seus membros do que essa mesma sociedade se entender sobre o que lhe é bom, justo, normal e moral.

O crime encarna o lado negativo do funcionamento social; ele revela que nem tudo está sob controle em uma sociedade e que a lei pode ser transgredida, ameaçando a harmonia desejada pela coletividade. A transgressão social figura entre os principais fatores desencadeadores de notícias, no jornalismo. Tal fenômeno se justifica, por um lado, pelo valor de novidade portado pelos atos transgressivos sempre alvos de curiosidade e interesse social, e, por outro, pela disposição do jornalismo de reiterar as condutas preconizadas como apropriadas e edificantes pela sociedade. 


\section{A transgressão como valor de notícia}

Em seu texto clássico, "O Mal-Estar na Civilização", Freud (1990, p.144-5) afirma que a "agressão constitui, no homem, uma disposição instintiva original e auto-subsistente" e "ela é o maior impedimento à civilização", a qual, essa sim, "constitui um processo a serviço de Eros".

O homem freudiano é um ser violento que só é domesticado à custa de regulações sociais impostas pela civilização que, dessa forma, se torna a maior fonte do sofrimento humano, uma vez que ela lhe impõe sacrifícios enormes no exercício de sua sexualidade e de sua agressividade. E, como o homem é impedido de exercer a sua natureza agressiva em sociedade, essa agressão se volta para o seu próprio ego e é assumida pelo superego. O superego faz com o ego o que este gostaria de fazer com os outros indivíduos (Freud, 1990).

Uma vez que o homem, para viver em sociedade, não pode dar vazão a sua carga de energia sexual, pois isso o levaria a sua própria destruição e inviabilizaria a construção e a solidificação cultural, esse potencial energético pulsional do ser humano tem de se dirigir a outros propósitos que não os explicitamente relacionados a sua sexualidade. A essa substituição do viés sexual pelo viés cultural, Freud (1990) denomina de sublimação. Nem todos os indivíduos são capazes de sublimar suas pulsões, mas, ainda que o façam, eles não eliminam totalmente as suas inclinações primitivas e subsistentes de natureza sexual.

O fato de o homem não poder exercer a sua sexualidade da forma como ele gostaria não quer dizer que não subsista nele a vontade de fazê-lo. Em outras palavras, por mais que a sociedade se incumba de atrofiar a natureza sexual e agressiva do homem, mediante normas de condutas morais que impeçam quaisquer possibilidades de satisfação plena nesse sentido, ela não consegue obter o sucesso que ela gostaria de ter nesse seu intento.

Assim, se o homem, por um lado, é obrigado a portar um sentimento de culpa constante manifestado na forma de "uma espécie de mal-estar" (Freud, 1990, p.60) cultural - porque ele deseja o que lhe é proibido -, por outro, a sociedade valida uma "moral sexual 'dupla'", isto é, permite a transgressão de suas normas, o que, segundo Freud, é "a melhor confissão de que a própria sociedade não acredita que seus preceitos possam ser obedecidos" (Freud, 1990, p.200).

Os padrões de civilização, segundo Freud, exigem de todos uma idêntica conduta sexual, a qual, se por alguns indivíduos, ela pode ser seguida sem dificuldades, para outros, ela impõe "os mais pesados sacrifícios psíquicos". Para sanar essa injustiça é que o homem desobedece às junções morais, tornando-se um criminoso, um outlaw (fora da lei) diante da sociedade ou, excepcionalmente, um grande homem, um herói (Freud, 1990).

O destino do homem que não se torna um outlaw (fora da lei) nem um herói é se contentar, então, em satisfazer as suas inclinações transgressoras nas suas fantasias. A fantasia ajuda o homem a suportar as suas frustrações com essa sociedade opressora. A fantasia é livre. O homem não necessita pagar nenhum preço à cultura por fantasiar. É na fantasia humana, então, que a transgressão se instala de forma mais confortável e menos arriscada.

Em seu Seminário 10, sobre a Angústia, Lacan (2005, p.60) afirma que "a fantasia do neurótico está inteiramente situada no lugar do Outro." Segundo Lacan, quando nos deparamos com essa fantasia, ela se apresenta a nós como perversão. Mas, embora os neuróticos tenham fantasias perversas, isso não é a mesma coisa que a perversão, explica Lacan, para quem as fantasias perversas dos neuróticos lhes servem "para se defender da angústia, para encobri-la" (Lacan, 2005, p.60).

A transgressão do outro já me serve: eu não preciso transgredir também. É esse o raciocínio que embasa a fantasia de transgressão do homem em sociedade. Assim, me é interessante que o outro rompa com a lei para que eu não necessite romper; já me satisfaz ver a transgressão do outro ou, mesmo, apenas saber da sua existência. Eu projeto no outro os meus anseios perversos.

Podemos localizar aí a curiosidade do ser humano pelas estórias transgressoras, e consiste precisamente nesse ponto o motivo de o jornalismo dotar de noticiabilidade os acontecimentos que transgridem as normas, as convenções, as leis, as condutas, a "moral sexual 'civilizada'" (Freud, 1990, p.187). 


\section{Valores-notícia e valores sociais}

A compreensão sustentada pela pesquisa é a de que os valores-notícia dos acontecimentos são uma decorrência particular e específica dos valores sociais conferidos aos fatos pela sociedade. Em outras palavras, entende-se aqui que a imprensa reifica o consenso social, reconhecendo-o, atualizando-o e devolvendo-o para a sociedade em forma de produto noticioso, de tal modo que os valores-notícia e os critérios substantivos das notícias reiteram os valores sociais em voga.

Esse atrelamento entre valores-notícia e valores sociais ocorre como uma consequência do lugar ocupado pela imprensa em sociedade: a imprensa está no meio das relações sociais nas quais ela tanto interfere como sofre delas interferências. O consenso social é, assim, fruto da atuação e da presença da imprensa na sociedade, sendo, portanto, uma construção ativa e ordinária do corpo social do qual a mídia é parte integrante.

A imprensa tende a conferir noticiabilidade aos fatos que, de alguma forma, já são valorizados pelo senso comum social o qual, com isso, pode reconhecer os valores-notícia da imprensa. É dessa forma que os critérios de noticiabilidade utilizados pelos jornalistas na sua função diária de produzir notícias são expedientes próprios da imprensa para responder: às necessidades, aos costumes, à moral, aos valores, à cultura, e também aos desejos, às fantasias, às curiosidades, aos medos, às inseguranças, enfim, de uma sociedade. Revelar esses critérios é desvendar a conversa que ela estabelece, rotineiramente, com o corpo social.

\section{A noticiabilidade do crime de exploração sexual infanto-juvenil}

A exploração sexual infanto-juvenil é um assunto que desperta a atenção da imprensa porque se enquadra dentro dos critérios substantivos relacionados à negatividade do acontecimento, os quais, para tanto, arregimentam os valores-notícia de transgressão, violação ou infração da ordem estabelecida. Tais características estão presentes em praticamente todos os tipos de crimes ou de práticas desviantes em sociedade e, quando se trata de um desvio que tem como alvo crianças e adolescentes, esse caráter transgressivo é ainda mais valorizado pela coletividade.

Reportagens que tratam de crimes cometidos contra crianças e adolescentes se substantivam na transgressão humana. Trata-se aí de uma transgressão social generalizada: a do agressor e a da vítima do crime de exploração sexual, obviamente, mas também a do leitor, a da imprensa e a da sociedade em geral. Estão todos de alguma forma imbricados na transgressão das normas, na extrapolação dos limites, ainda que em graus e de maneiras diferentes.

Enquanto o acontecimento em si é transgressor porque, basicamente, desconhece qualquer lei, a imprensa é especialmente transgressora porque avança em direção ao novo, ou seja, possibilita uma (re) visão inovadora da questão por parte da sociedade, a qual, por sua vez, transgride também ao (re) avaliar o problema noticiado pela mídia, sob uma nova ótica e, quem sabe, a partir de um outro lugar social.

Ao mesmo tempo, toda a sociedade, quando trata do tema da exploração sexual de crianças e adolescentes, se envolve na trama freudiana e lacaniana da transgressão, no sentido de que torna possível assistir à transgressão do outro sem dela necessitar participar diretamente. Essa não deixa de ser uma equação perversa realizada pela sociedade, mas que, de acordo com os pressupostos psicanalíticos, compensa e equilibra o funcionamento social.

A noção de que as transgressões humanas são notícias já está completamente introjetada no jornalismo. Não é por acaso que os teóricos da comunicação classificam a "transgressão" como um valor-notícia encampado pelo critério substantivo de noticiabilidade, ou seja, um valor duradouro, centralizador e de grande reconhecimento e respaldo social. Então, esse tipo de crime é notícia não porque os jornalistas assim o querem e o selecionam, numa iniciativa unidirecional, mas porque os jornalistas reconhecem nesse tipo de acontecimento um valor conferido socialmente. 
A seleção feita pelo jornalismo, no caso dos acontecimentos de significativo valor substantivo, é uma reiteração do que a sociedade, consensualmente, já selecionou como fato relevante. O que o jornalismo faz é evidenciá-lo, atualizá-lo para o conhecimento do público, denunciá-lo, endossando esse consenso social.

Afinal, a mídia não existe separada da sociedade. Uma e outra se entendem sobre os valores, crenças, tradições e transformações sociais. É graças a essa condição que ela consegue repercutir os fatos sociais de forma sintonizada com o senso comum e se fazer reconhecida por este.

Tomando como referência o disposto por Freud sobre a condição bárbara subsistente no homem civilizado, pode-se dizer que, de um modo geral, todas as informações jornalísticas noticiadas com base no valor-notícia da transgressão social, ao municiarem a sociedade de material que lhe possibilite transgredir na fantasia - e, com isso, sublimar o desejo de uma transgressão real -, contribuem para a estabilidade do funcionamento da sociedade no que diz respeito às suas regras de conduta de comportamento sexual.

Ou seja: as reportagens sobre crimes sexuais endossam e reforçam o consenso social sobre o que é permitido e o que não é permitido em sociedade a respeito do exercício da sexualidade dos indivíduos, possibilitando à imprensa ficar moralmente consoante com os valores defendidos pela sociedade, numa clara demonstração de harmonia entre os critérios de noticiabilidade da imprensa e os valores fundamentais definidos pela sociedade.

A imprensa não se coloca na contramão social. A sua função é, basicamente, fortalecer os pressupostos considerados importantes socialmente e, assim, ajudar a cumprir com os dispositivos legais e morais que embasam o funcionamento da sociedade.

\section{Conclusões}

Nas estradas que cortam o estado de Minas Gerais, uma parcela de crianças e adolescentes comercializam seus corpos, perdem sua inocência, dilaceram seus sonhos, abandonam toda a sua esperança, experimentam o que de pior a vida pode oferecer-Ihes: a degradação generalizada. Uma degradação que é física e moral; individual, íntima e particular, mas também coletiva e social, uma vez que a degeneração que lhes atinge envergonha e humilha toda uma sociedade que permite tal realidade. Essa realidade é o resto, o resíduo social que preferimos não enxergar, tampouco tomar conhecimento de sua existência, mas que está ali, bem perto de nós, nos postos de gasolina, restaurantes, boates e prostíbulos de beira de estrada.

Há um entendimento social sendo aperfeiçoado - pelo menos junto à parcela da sociedade brasileira que tem acesso à informação - de que a exploração sexual infanto-juvenil é um crime que merece ser denunciado e punido. O campo comunicacional tem tido um papel fundamental no processo de denunciar o problema, responsabilizando o poder público na busca por soluções e contribuindo para a conscientização da sociedade sobre a questão.

Concorre, para a construção desse consenso social, a vigência, no país, desde 13 de julho de 1990, do Estatuto da Criança e do Adolescente (ECA), que reflete e ampara, na lei, uma nova noção jurídica sobre a infância e a adolescência, tornando-a uma responsabilidade do Estado, da família e da sociedade. O lugar da criança e do adolescente na sociedade brasileira passou a ser, em conformidade com o ECA, de sujeitos de direitos exigíveis em lei.

Submetida que é à sina da atualidade e, portanto, à condição de necessária sintonia com a sociedade em que se acha inserida, a instância comunicacional brasileira tem conferido noticiabilidade à realidade experimentada pelas crianças e adolescentes porque o universo infanto-juvenil tem conquistado importância e relevância sociais, ou seja, tem se arregimentado de critérios substantivos capazes de, cada vez mais, se impor à cobertura cotidiana da imprensa nacional.

Dados da Rede ANDI Brasil - uma agência voltada para o monitoramento da cobertura da imprensa dos diversos temas pertinentes ao universo infanto-juvenil - informam que, entre 1996 e 2004, houve um aumento de $1.148,74 \%$ no número de notícias sobre crianças e adolescentes publicadas por 45 veículos de comunicação impressa (jornais e revistas) nacionais (ANDI, 2005). 
${ }^{6}$ Dados informados pelo Relatório Infância na Mídia - a criança e o adolescente no olhar da imprensa brasileira. Relatório 2003/2004

${ }^{7}$ Dados informados pela pesquisa "A criança e o adolescente na mídia - MG" (Oficina de Imagens, 2006).
Foi auferido pela Rede ANDI Brasil que, em 1996, enquanto 55 jornais produziram 10.700 notícias referentes ao universo infanto-juvenil, em 2000, esse número saltou para 64.396 inserções produzidas por cinquenta veículos impressos, chegando, em 2004, a um total de 161.706 inserções informativas realizadas por setenta meios de comunicação impressa: sessenta jornais e dez revistas. $^{6}$

Em Minas, a ONG "Oficina de Imagens" apurou que, entre 2001 e 2004, houve um crescimento de mais de $80 \%$ na quantidade de matérias publicadas sobre crianças e adolescentes em oito jornais pesquisados, de modo que a mídia impressa mineira, em 2004, publicou, de acordo com os dados da Oficina, pelo menos 14.887 textos referentes ao universo infanto-juvenil. ${ }^{7}$

Dessa forma é que se pode afirmar que a consensualidade sobre o tema da exploração sexual infanto-juvenil está diretamente relacionada com a sua noticiabilidade jornalística, e ambos se encontram em processo de construção e fortalecimento impulsionado pela vigência e implementação do Estatuto da Criança e do Adolescente.

As análises da noticiabilidade das reportagens selecionadas para a pesquisa nos permitem concluir que elas são consideradas e reconhecidas publicamente como reportagens porque se enquadram dentro de um formato gráfico e textual especificamente jornalístico; que elas são todas reportagens oportunas socialmente, isto é, foram realizadas dentro de uma ambiência social familiar, conectada aos acontecimentos ordinários, e não impostas ao público de modo aleatório, maquiavélico ou na contramão das expectativas da sociedade; e que, na condição de reportagens que tratam de um tema negativo e transgressor, por excelência, como é o caso da exploração sexual infanto-juvenil, elas transgridem duplamente. A dupla transgressão operacionalizada por esse tipo de notícia ocorre na medida em que toda notícia é um produto jornalístico naturalmente transgressor, uma vez que ela se instala sempre no que rompe com a normalidade do funcionamento social. Quando a notícia, para além de sua natureza imperiosamente transgressora, aborda um acontecimento também transgressor, ela se torna transgressora em dobro.

O jornalismo transgride ao noticiar a transgressão humana mas, nem por isso, ele se envolve na transgressão das leis sociais. Ao selecionar como noticiáveis acontecimentos relativos ao crime de exploração sexual infanto-juvenil, o jornalismo atende a uma necessidade básica e subsistente do ser humano, que é a da transgressão sob todas as suas formas.

Assim, ao reportar a transgressão sexual, o jornalismo acaba por reafirmar as fronteiras entre o que é consensualmente aceitável e o que deve ser condenável socialmente em se tratando do comportamento sexual humano. Ou seja, a notícia transgride para apaziguar, normalizar, ajustar o funcionamento social às suas leis e às suas normas.

Esse deslocamento de sentido e de função social operacionalizado pelo jornalismo e objetivado especialmente nas notícias sobre acontecimentos transgressores, é possibilitado pelo fato de a notícia ser, ela própria, um outro acontecimento que porta do acontecimento originário apenas alguns poucos elementos, pois a notícia se faz acontecer socialmente de uma maneira própria e única.

A notícia, como um produto que opera com a consensualidade social, transforma os acontecimentos transgressores em acontecimentos-notícia que acontecem para reforçar as convenções aceitas e defendidas em sociedade. Isso quer dizer que a notícia rompe com a normalidade do cotidiano não para tumultuar ainda mais esse cotidiano, mas para normalizá-lo, para torná-lo inteligível e possível de ser assimilado pela coletividade. 
No caso das reportagens analisadas pela pesquisa, o crime de exploração sexual de crianças e adolescentes é abordado sob a ótica da lei, ou seja, de que existem vítimas - as crianças e adolescentes abusados - e culpados - os abusadores. Pautando-se pelo entendimento jurídico e legal, a imprensa dá a sua quota de contribuição para a construção do consenso social sobre o assunto.

As investigações sobre a noticiabilidade das reportagens selecionadas para a pesquisa demonstraram que o processo de seleção e produção da notícia é um processo sempre contextualizado no social, que leva em conta os costumes, a moral, os valores, a cultura, enfim, de uma coletividade, e que também responde aos desejos, às fantasias, às curiosidades, aos medos e às inseguranças próprias do ser humano.

Assim, a noticiabilidade é um processo noticioso humanizador do jornalismo, a despeito de ser também um expediente técnico operado por especialistas que são os jornalistas. Ademais, é justamente porque a noticiabilidade é operacionalizada por jornalistas e destina-se a alcançar o público, que ela se caracteriza, sobretudo, como um processo humanizado.

\section{Colaboradores}

Os autores trabalharam juntos em todas as etapas de produção do manuscrito.

\section{Referências}

Agência de Notícias dos Direitos da Infância. Pauta para novos tempos: infância na mídia - a criança e o adolescente no olhar da imprensa brasileira. Relatório 2003/2004, v.10, n.14, p.5, 2005.

ARAÚJO, I.; CARDOSO, J. Comunicação e saúde. Rio de Janeiro: Fiocruz, 2007.

CAMPOS, M.A.T.F. A infância sem segredos: a noticiabilidade jornalística do crime de exploração sexual de crianças e adolescentes. 2008. Dissertação (Mestrado) - Universidade Federal de Minas Gerais, Belo Horizonte. 2008.

FREUD, S. O mal-estar na civilização. In: STRACHEY, J. (Ed.). Trad. José Octávio de Aguiar Abreu. Obras psicológicas completas de Sigmund Freud. 3.ed. Rio de janeiro: Imago, 1990. p.75-171.

A negativa, o ego e o id. In: STRACHEY, J. (Ed.). Trad. Vera Ribeiro. Obras psicológicas completas de Sigmund Freud. 3.ed. Rio de Janeiro: Imago, 1990. p. 23-76.

. Moral sexual 'civilizada' e doença nervosa moderna. In: STRACHEY, J. (Ed.). Trad. Maria Aparecida Moraes Rego. Obras psicológicas completas de Sigmund Freud. 3.ed. Rio de Janeiro: Imago, 1990. p.185-208.

HALL, S. et al. A produção social das notícias: o mugging nos media. In: TRAQUINA, N. Jornalismo: questões, teorias e estórias. Lisboa: Vega, 1993. p.224-8.

LACAN, J. Angústia: além da angústia de castração.In: MILLER, J.A. (Ed.). Trad. Vera Ribeiro. O seminário. Livro 10. Rio de Janeiro: Jorge Zahar, 2005. p.53-65.

ODILLA, F. et al. Infância roubada. Jornal Estado de Minas, Belo Horizonte, 2 maio 2004. Caderno Gerais, p.25-9.

OFICINA DE IMAGENS. Infância consolida espaço na imprensa mineira. A criança e o Adolescente na Mídia-MG, v.5, n.5, p.9, 2006. Especial ECA 15 anos. 
TRAQUINA, N. Teorias do Jornalismo: a tribo jornalística - uma comunidade interpretativa transnacional. Florianópolis: Insular, 2005. v.2.

WOLF, M. Teorias das comunicações de massa. São Paulo: Martins Fontes, 2005.

CAMPOS, M.A.T.F; VIEIRA, C.D.D.; MOTA, J.A.C. La infancia sin secretos: el noticiario periodístico del crimen de explotación sexual de niños y adolescentes. Interface -

Comunic., Saude, Educ., v.13, n.30, p.17-29, jul./set. 2009.

Al seleccionar los acontecimientos ordinarios que la sociedad debe conocer y los que debe ignorar y al codificar estos acontecimientos en forma de noticia, el periodismo coloca a disposición de la colectividad un tipo de experiencia con el mundo que la cerca. Cada vez más los dispositivos comunicativos son los medios de experiencia del hombre civilizado. Conocer la naturaleza de tal experiencia es una forma de que la sociedad se apropie de su propio funcionamiento y de su propia condición. Esta investigación trabaja con 15 reportajes publicados por el periódico Jornal Estado de Minas, Brasil, en 2004; especialmente con el gran reportaje Infancia Robada. Por medio de la estrategia de desconstrucción estética y de la narrativa noticiosa de Infancia Robada, así como del análisis de contenido del material, se pone en evidencia que el valor-noticia de la transgresión es lo que justifica la condición de noticiable en los periódicos de los crímenes sexuales cometidos contra niños y adolescentes.

Palabras clave: Violencia sexual. Malos tratos sexuales infantiles. Medios de comunicación. Niño. Adolescente. 